\title{
Comparison of methods for the
} CrossMark identification of microorganisms isolated
from blood cultures

\author{
Aydir Cecília Marinho Monteiro', Carlos Magno Castelo Branco Fortaleza², Adriano Martison Ferreira ${ }^{3}$, \\ Ricardo de Souza Cavalcante ${ }^{4}$, Alessandro Lia Mondelli ${ }^{5}$, Eduardo Bagagli ${ }^{1}$ and \\ Maria de Lourdes Ribeiro de Souza da Cunha ${ }^{1,2^{*}}$
}

\begin{abstract}
Background: Bloodstream infections are responsible for thousands of deaths each year. The rapid identification of the microorganisms causing these infections permits correct therapeutic management that will improve the prognosis of the patient. In an attempt to reduce the time spent on this step, microorganism identification devices have been developed, including the VITEK ${ }^{\circledR} 2$ system, which is currently used in routine clinical microbiology laboratories.

Methods: This study evaluated the accuracy of the VITEK ${ }^{\circledR} 2$ system in the identification of 400 microorganisms isolated from blood cultures and compared the results to those obtained with conventional phenotypic and genotypic methods. In parallel to the phenotypic identification methods, the DNA of these microorganisms was extracted directly from the blood culture bottles for genotypic identification by the polymerase chain reaction (PCR) and DNA sequencing.

Results: The automated VITEK ${ }^{\circledR} 2$ system correctly identified $94.7 \%$ (379/400) of the isolates. The YST and GN cards resulted in $100 \%$ correct identifications of yeasts (15/15) and Gram-negative bacilli (165/165), respectively. The GP card correctly identified $92.6 \%$ (199/215) of Gram-positive cocci, while the ANC card was unable to correctly identify any Gram-positive bacilli (0/5).
\end{abstract}

Conclusions: The performance of the VITEK ${ }^{\circledR} 2$ system was considered acceptable and statistical analysis showed that the system is a suitable option for routine clinical microbiology laboratories to identify different microorganisms.

Keywords: Blood culture, Phenotypic identification, Genotypic identification, Automated VITEK ${ }^{\circledR}$ system

\section{Background}

Sepsis is a global health problem and an estimated 17 million cases of sepsis occur each year in the world [1]. The early initiation of appropriate antibiotic therapy is determinant for the prognosis and survival of patients with bloodstream infections [2]. Patients receiving antibiotic therapy that is adapted based on the susceptibility profile of the infectious agent isolated from blood

\footnotetext{
*Correspondence: cunhamlr@ibb.unresp.br

${ }^{1}$ Departamento de Microbiologia e Imunologia, Instituto de Biociências de Botucatu, UNESP-Univ. Estadual Paulista, Distrito de Rubião Junior, s/n, Botucatu, SP CEP: 18618-970, Brazil

Full list of author information is available at the end of the article
}

cultures exhibit lower mortality than those treated initially with inadequate antibiotic therapy [3]. In addition, technological advances that permit the rapid and reliable identification of most pathogens involved in infectious diseases have long been recognized to have clinical benefits, including shorter hospital stays and lower mortality, as well as financial benefits by reducing healthcare costs [4].

The objective of this study was to evaluate the sensitivity of the VITEK ${ }^{\circledR} 2$ system, a system that automatically performs the processes required for microorganism identification and for the determination of antimicrobial susceptibility using a standard primary inoculum isolated from subcultures of positive 
blood cultures. Although classical identification methods are still considered the gold standard, these methods are slow, time consuming and prone to subjective interpretations. On the other hand, the VITEK ${ }^{\circledR} 2$ system reduces the time necessary for identification and permits the standardization of inter- and intra-laboratory results, the storage of results, issuing rapid epidemiological reports, and simultaneous identification and antimicrobial susceptibility testing; however, the system is poorly efficient in identifying certain species of Gram-positive cocci [42].

Studies using direct inoculation of VITEK ${ }^{\circledR} 2$ cards from blood culture bottles have been conducted in an attempt to further reduce the time of identification of microorganisms that cause bloodstream infections, but the results were acceptable only for Gram-negative bacilli and were inaccurate for Gram-positive cocci [5, 6]. For this reason, the present study used inocula of microorganisms cultured previously on solid media for $24 \mathrm{~h}$.

The difference of this study was the prospective evaluation of the VITEK ${ }^{\circledR} 2$ system during the routine work of a clinical microbiology laboratory in a university hospital using 400 microorganisms isolated from blood cultures collected during the hospitalization period of patients rather than to conduct a retrospective study of samples stored for years.

\section{Methods}

\section{Isolates studied}

Four hundred microorganisms isolated from positive blood cultures of patients hospitalized in intensive care units of the Botucatu University Hospital between August 2012 and February 2014 were identified. The blood samples were inoculated into blood culture bottles and incubated in the $\mathrm{BACTEC}^{\mathrm{TM}} 9050$ apparatus.

\section{Identification of microorganisms in positive blood cultures Automated phenotypic identification}

Samples exhibiting microbial growth were submitted to Gram staining and cultured on solid media directly from the blood culture bottles. After subculture on blood and MacConkey agar, the isolates were inoculated into the following specific identification cards of the automated VITEK $^{\circledR} 2$ system using the standard protocol: Grampositive cocci (GP), Gram-positive bacilli (GN), Gramnegative bacilli (ANC), and yeasts (YST). Gram-positive cocci, Gram-positive bacilli and yeast were inoculated into the cards from colonies grown on blood agar and Gram-negative bacilli from colonies grown on MacConkey agar, all diluted in saline $(0.9 \% \mathrm{NaCl})$ to a 0.5 McFarland standard.

\section{Phenotypic identification by conventional methods}

Phenotypic identification consisted of Gram staining for the observation of morphology and specific staining, followed by a series of biochemical tests specific for each group of microorganisms. Gram-positive cocci were submitted to the catalase test for differentiation between Staphylococcus and Enterococcus. The following biochemical test battery was used for the identification of species of the genus Staphylococcus: coagulase, sugar fermentation (sucrose, maltose, trehalose, xylose, and mannitol), anaerobic growth on semi-solid sodium thioglycolate medium and, if necessary, ornithine and urease production and novobiocin susceptibility [7]. Isolates previously identified as Gram-positive, catalase-negative, bile esculin-positive, $\mathrm{NaCl}$-positive (growth in brain heart infusion broth with $6.5 \% \mathrm{NaCl}$ ) and pyrrolidonylaminopeptidase test-positive cocci were submitted to biochemical tests of fermentation of mannitol, arabinose, arginine and sorbitol, motility, and presence or absence of a pigment on sheep blood agar. Gram-negative bacilli were first tested for glucose fermentation. Glucose-fermenting bacilli were submitted to manual biochemical tests known as EPM/MILi/Citrate, an identification system based on the following tests: production of $\mathrm{H}_{2} \mathrm{~S}$, urease and L-tryptophan desaminase; motility; indol production; lysine decarboxylase production, and the ability to use citrate as a single carbon source. Non-glucose-fermenting Gram-negative bacilli were identified based on motility, growth at a temperature of $42{ }^{\circ} \mathrm{C}$, and production of DNAse. Yeasts were isolated on Sabouraud agar, replated on CHROMagar, and identified based on the color, texture and shape of their colonies [8].

\section{DNA extraction from the isolates}

Extraction of bacterial DNA Bacterial DNA was extracted directly from the blood sample of the blood culture bottle using the Illustra Kit (GE Healthcare) according to the protocol of the manufacturer, with modifications in the first centrifugation [9] and the addition of $800 \mu \mathrm{L}$ benzyl alcohol [10]. For sample collection, the lid of the blood culture bottle was first disinfected with cotton soaked in $70 \%$ alcohol. Next, $1.5 \mathrm{~mL}$ of the culture was aspirated with a sterile needle and syringe and transferred to sterile microtubes. The microtubes were centrifuged at $850 \mathrm{~g}$ for $2 \mathrm{~min}$ and the supernatant was removed by aspiration with a micropipette and sterile tips and the supernatant stored (directly in a DNA-free microtube) at $-20^{\circ} \mathrm{C}$ until the time of extraction.

For DNA extraction, the sample was centrifuged at $10,000 \mathrm{~g}$ for $1 \mathrm{~min}$, the supernatant was discarded, and $500 \mu \mathrm{L}$ lysozyme was added to the sediment. The mixture was vortexed, $800 \mu \mathrm{L}$ benzyl alcohol was added, and 
the mixture was again shaken and centrifuged at $7000 \mathrm{~g}$ for $5 \mathrm{~min}$. Next, $300 \mu \mathrm{L}$ of the supernatant was carefully removed and transferred to a new sterile microtube (which was used for extraction). Ten microliter lysozyme $(10 \mathrm{mg} / \mathrm{mL})$ was added and the microtube was left to stand at room temperature for $15 \mathrm{~min}$, with vortexing every $5 \mathrm{~min}$. After this period, $10 \mu \mathrm{L}$ proteinase $\mathrm{K}(20 \mathrm{mg} / \mathrm{mL})$ was added and the mixture was vortexed. The microtube was incubated for $15 \mathrm{~min}$ at $56{ }^{\circ} \mathrm{C}$, with vortexing every $5 \mathrm{~min}$. This mixture was then transferred to an extraction microcolumn and centrifuged at $11,000 \mathrm{~g}$ for $1 \mathrm{~min}$. The filtrate was discarded and $500 \mu \mathrm{L}$ washing solution was added to the microcolumn. The column was again centrifuged at $11,000 \mathrm{~g}$ for $3 \mathrm{~min}$. The supernatant was discarded, the microcolumn was transferred to a new sterile microtube, and $200 \mu \mathrm{L}$ Milli-Q water previously heated to $70{ }^{\circ} \mathrm{C}$ was added. The microcolumn was kept at room temperature for $1 \mathrm{~min}$ and centrifuged at $11,000 \mathrm{~g}$ for $1 \mathrm{~min}$. The columns were discarded and the filtered material was frozen until analysis by the polymerase chain reaction (PCR).

Extraction of yeast DNA Yeast DNA was extracted according to the protocol proposed by McCullough et al. [11]. The isolates were seeded onto inclined Sabouraud agar and incubated for $36 \mathrm{~h}$ at $37^{\circ} \mathrm{C}$. A loopful of this culture was resuspended in a $2-\mathrm{mL}$ tube containing $1 \mathrm{~mL} 1 \mathrm{M}$ sorbitol, $125 \mathrm{mM}$ EDTA, and $500 \mathrm{mg}$ glass beads. The tube was shaken twice in a Precellys ${ }^{\circledR}$ homogenizer for $45 \mathrm{~s}$ and centrifuged at $13,000 \mathrm{~g}$ for $10 \mathrm{~min}$. The supernatant was discarded and the sediment together with the glass beads was resuspended in $500 \mu \mathrm{L}$ of a buffer solution containing $50 \mathrm{mM}$ Tris- $\mathrm{HCl}, 50 \mathrm{mM}$ EDTA and $2 \%$ SDS and incubated for $1 \mathrm{~h}$ at $65{ }^{\circ} \mathrm{C}$. After incubation, $500 \mu \mathrm{L} 3 \mathrm{M}$ sodium acetate was added. The mixture was homogenized by inverting the tube and kept on ice for $2 \mathrm{~h}$, followed by centrifugation for $10 \mathrm{~min}$ at $25^{\circ} \mathrm{C}$. The supernatant was transferred to a $1.5-\mathrm{mL}$ centrifugation microtube containing $1 \mathrm{~mL}$ ice-cold absolute ethanol, homogenized by inversion, and centrifuged for $10 \mathrm{~min}$ at $4{ }^{\circ} \mathrm{C}$. The supernatant was discarded and the DNA retained on the tube wall was resuspended in $50 \mu \mathrm{L}$ autoclaved Milli-Q water and frozen until the time of PCR.

\section{Genotypic identification of the isolates}

Polymerase chain reaction of bacteria Gram-positive bacteria of the genus Staphylococcus that belonged to the group of coagulase-negative staphylococci (CoNS) were identified by internal transcribed spacer PCR (ITS$\mathrm{PCR}$ ) using primers targeting conserved sequences adjacent to the $16 \mathrm{~S}$ and $23 \mathrm{~S}$ genes: G1 (5'-GAAGTCGT AACAAGG-3') and L1 (5'-CAAGGCATCCACCGT-3') $[12,13]$.
The remaining isolates of Gram-positive cocci and Gram-negative bacilli were submitted to PCR carried out in $0.2-\mathrm{mL}$ microtubes containing $15.8 \mu \mathrm{L}$ Milli-Q water, $10 \mathrm{pM}$ of the forward primer and $10 \mathrm{pM}$ of the reverse primer, $100 \mu \mathrm{M}$ triphosphate desoxyribonucleotides (GE Healthcare), $10 \mathrm{U}$ Taq DNA polymerase (Biotools), $20 \mathrm{mM} \mathrm{MgCl} 2$-free buffer (Biotools), $0.75 \mathrm{mM} \mathrm{MgCl}_{2}$ (Biotools), and $3 \mu \mathrm{L}$ DNA. Primers targeting conserved sequences of each species were used for DNA amplification. The temperature and time parameters and number of amplification cycles reported in the literature and described in Table 1 were used.

The efficiency of the amplifications was monitored by electrophoresis on $2 \%$ agarose gel prepared in $1 \times \mathrm{TBE}$ buffer ( $89 \mathrm{mM}$ Tris ( $\mathrm{pH} 7.6$ ), $89 \mathrm{mM}$ boric acid, and $2 \mathrm{mM}$ EDTA) and stained with $\mathrm{SYBR}^{\circledR}$ Safe at $90 \mathrm{~V}$ for 60 min (Figs. 1, 2). The following international reference strains were used as controls: Acinetobacter baumannii (ATCC 19606), Enterobacter cloacae (ATCC 23355), Enterococcus faecalis (ATCC 29212), Enterococcus faecium (ATCC 6569), Escherichia coli (ATCC 10536), Klebsiella pneumoniae (ATCC 4352), Morganella morganii (ATCC 8019), Proteus mirabilis (ATCC 15290), Pseudomonas aeruginosa (ATCC 15442), Serratia marcescens (ATCC 14756), Staphylococcus aureus (ATCC 25923), and Stenotrophomonas maltophilia (ATCC 13637).

Figures 1 and 2 illustrate the genotypic identification of Enterobacter cloacae and Escherichia coli, respectively.

DNA sequencing of bacteria The yeast and Gram-positive bacillus isolates were sequenced for identification to species level. Gram-negative bacilli identified as Enterobacter aerogenes by the conventional phenotypic methods and by the automated test were sequenced for species confirmation.

Amplification and purification of bacterial DNA for sequencing The bacterial isolates identified as Grampositive bacilli by Gram staining and the Gram-negative bacilli identified as Enterobacter aerogenes by the conventional phenotypic methods and automated test were submitted to simple PCR. The efficiency of the reactions was monitored as described in item 2.4.1. For PCR, protocols described in the literature were followed using universal primers for Gram-positive bacilli [14] and primers of enterobacteria for Enterobacter aerogenes isolates [15]. The temperature and time parameters and number of amplification cycles are shown in Table 1 . The amplified DNA fragments were purified using the HiYield Gel/PCR DNA Fragments Extraction Kit (RBC).

Amplification and purification of yeast DNA The yeast isolates were submitted to ITS-PCR as described by 
Table 1 Primers used for the identification of some bacterial species by PCR

\begin{tabular}{|c|c|c|c|c|}
\hline Microorganism & Gene & Annealing temperature $\left({ }^{\circ} \mathrm{C}\right)$ & Amplicon size (bp) & Reference \\
\hline Acinetobacter baumannii & blaOXA_51-like & 52 & 353 & {$[44]$} \\
\hline Acinetobacter Iwoffii & 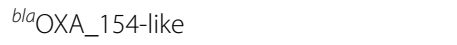 & 52 & 223 & {$[45]$} \\
\hline Enterobacter cloacae & Hsp60 (housekeeping) & 52 & 343 & {$[46]$} \\
\hline Enterococcus faecalis & 165 chromosomal region & 60 & 143 & {$[47]$} \\
\hline Enterococcus faecium & sodA (superoxide dismutase) & 45 & 216 & {$[21]$} \\
\hline Escherichia coli & gadA (alpha-glutamate decarboxylase) & 65 & 373 & {$[48]$} \\
\hline Klebsiella pneumoniae & rpoB ( $\beta$ subunit of RNA polymerase) & 52 & 364 & {$[49]$} \\
\hline Morganella morganii & $16 S$ chromosomal region & 62 & 809 & {$[50]$} \\
\hline Proteus mirabilis & rsbA (quorum sensing) & 55 & 236 & {$[51]$} \\
\hline Pseudomonas aeruginosa & Genome fragment & 55 & 724 & {$[52]$} \\
\hline Serratia marcescens & $16 S$ chromosomal region & 52 & 1058 & {$[53]$} \\
\hline Staphylococcus aureus & 165 chromosomal region & 52 & 442 & {$[54]$} \\
\hline Stenotrophomonas maltophilia & atpD (housekeeping) & 52 & 854 & {$[55]$} \\
\hline Bacillus spp. & rpoB ( $\beta$ subunit of RNA polymerase) & 72 & 400 & [14] \\
\hline Enterobacter aerogenes & $16 \mathrm{SrDNA}$ & 55 & 280 & {$[15]$} \\
\hline
\end{tabular}

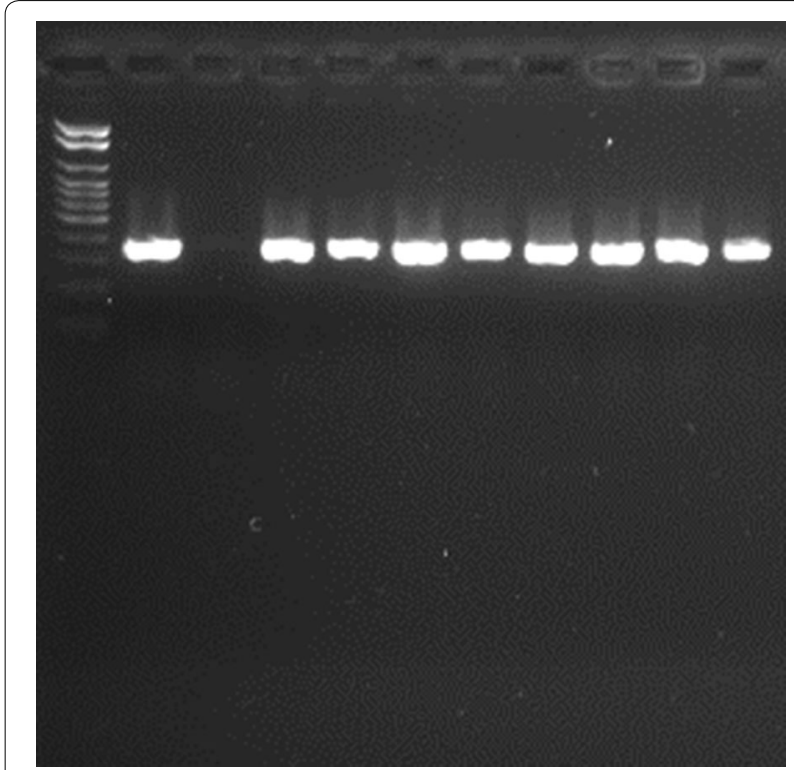

Fig. 1 Agarose gel electrophoresis for detection of Hsp60 (343 bp) in Enterobacter cloacae (stained with SYBR ${ }^{\circledR}$ Safe) showing the amplified products positive control, negative control and some samples studied. A 100-bp ladder was used as molecular size marker

Kurtzman et al. [16]. These reactions were carried out in 0.2-mL microtubes containing a mixture of $6.7 \mu \mathrm{L}$ Milli-Q water, $10 \mu \mathrm{M}$ forward primer and $10 \mu \mathrm{M}$ reverse primer, $12.5 \mu \mathrm{L}$ GoTaq $^{\circledR}$ Green Master Mix, and $3 \mu \mathrm{L}$ DNA. The efficiency of the amplifications was monitored by electrophoresis $(60 \mathrm{~min}, 80 \mathrm{~V}$ ) on $1.5 \%$ agarose gel prepared in $1 \times$ TBE buffer and stained with $\mathrm{SYBR}^{\circledR}$ Safe. Strains previously identified at the Laboratory of Fungal Biology,
Department of Microbiology and Immunology, IBB, were used as controls. The amplified fragments were purified using the Illustra ${ }^{\mathrm{TM}}$ ExoProStar $^{\mathrm{TM}}$ Kit (GE Healthcare Life Sciences).

DNA sequencing reaction of yeast and bacteria The sequencing reactions were carried out in a mixture containing 3.25 $\mu \mathrm{L}$ water, $1.75 \mu \mathrm{L} 5 \times$ BigDye buffer (Applied Biosystems), $1 \mu \mathrm{L}$ of each primer $(5 \mathrm{pmol} / \mu \mathrm{L}), 2 \mu \mathrm{L}$ of the PCR product, and $2 \mu \mathrm{L}$ BigDye (Applied Biosystems). The cycle sequencing reaction was initiated at $96^{\circ} \mathrm{C}$ for $1 \mathrm{~min}$, followed by 40 cycles of denaturation at $96{ }^{\circ} \mathrm{C}$ for $30 \mathrm{~s}$, annealing at $60{ }^{\circ} \mathrm{C}$ for $30 \mathrm{~s}$ and extension at $72{ }^{\circ} \mathrm{C}$ for $4 \mathrm{~min}$. The sequencing reaction product was precipitated with $1 \mu \mathrm{L} 125 \mathrm{mM}$ EDTA, $1 \mu \mathrm{L} 3 \mathrm{M}$ sodium acetate, and $25 \mu \mathrm{L}$ $100 \%$ ethanol. After homogenization, the solution was left to stand for $15 \mathrm{~min}$ and then centrifuged at $3000 \mathrm{~g}$ for $15 \mathrm{~min}$ at $4{ }^{\circ} \mathrm{C}$. The supernatant was removed by inverting the tube and $35 \mu \mathrm{L} 70 \%$ ethanol was added. The solution was centrifuged at $1650 \mathrm{~g}$ for $15 \mathrm{~min}$ at $4{ }^{\circ} \mathrm{C}$. After removal of the supernatant by inversion, $10 \mu \mathrm{L} \mathrm{HiDi}$ formamide (Applied Biosystems) was added and the mixture was left to stand for $5 \mathrm{~min}$ at $95^{\circ} \mathrm{C}$ and for $2 \mathrm{~min}$ on ice. The product was run on an 8-capillary ABI 3500 sequencer $(50 \mathrm{~cm})$ using POP7 polymer (Applied Biosystems).

Analysis of the DNA sequences of yeast and bacteria The MEGA 5.0 (Molecular Evolutionary Genetics Analysis) and Lasergene programs were used for visualization and alignment of the DNA sequences obtained, which were compared to sequences published and stored in the GenBank database. 


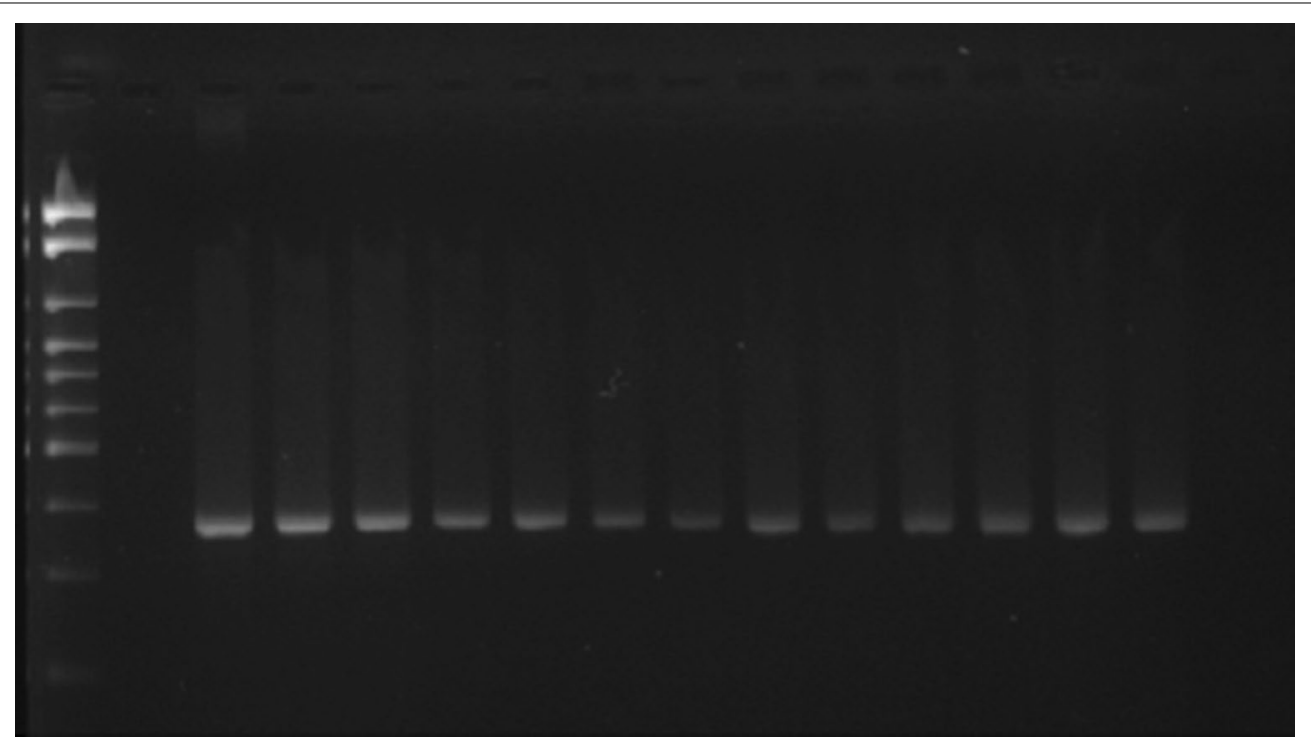

Fig. 2 Agarose gel electrophoresis for detection of gadA (373 bp) in Escherichia coli (stained with SYBR ${ }^{\circledR}$ Safe) showing the amplified products positive control, negative control and some samples studied. A 100-bp ladder was used as molecular size marker

\section{Statistical analysis}

Agreement between the results obtained with the different identification methods was analyzed statistically by the kappa test using the SPSS 20 program (IBM, Armonk, NY, USA). Genotypic identification was used as the gold standard. The accuracy of the conventional phenotypic identification methods and identification by the VITEK ${ }^{\circledR}$ 2 system was evaluated by calculating sensitivity and specificity according to Fletcher et al. [17].

\section{Results}

The results of identification with the automated VITEK ${ }^{\circledR}$ 2 system showed overall agreement of $94.7 \%$ with the results of the genotypic methods (Tables 2, 3). Overall agreement of $98.7 \%$ was observed between the results obtained by phenotypic identification using conventional methods and the results of the genotypic methods.

All yeast isolates (15/15) were correctly identified by the VITEK ${ }^{\circledR} 2$ system using the YST card. The same result was obtained with the GN card for the identification of Gram-negative bacilli, with $100 \%$ correct identifications of the 165 strains isolated.

The rate of correct identification obtained with the GP card used for the identification of Gram-positive cocci was $92.6 \%$ for the microorganisms isolated (199/215). The agreement between the results of automated identification and those obtained with the other identification methods for Enterococcus spp. was $91.7 \%$ due to the incorrect identification of one Enterococcus faecalis strain by the VITEK ${ }^{\circledR} 2$ system. The agreement between species of the genus Staphylococcus was $97.5 \%$ (198/203). The
VITEK $^{\circledR} 2$ system correctly identified all Staphylococcus aureus isolates (17/17) and incorrectly identified 15 of the 186 (9.19\%) isolates belonging to the group of CoNS. The highest rate of incorrect identification was observed for Enterococcus faecalis with 12.5 \% (7/8), followed by Staphylococcus epidermidis with $12.3 \%$ (10/81), Staphylococcus hominis with $8.6 \%(3 / 35)$, Staphylococcus capitis with $5.5 \%$ (1/18), and Staphylococcus haemolyticus with $2 \%(1 / 50)$.

The VITEK ${ }^{\circledR} 2$ system incorrectly identified the isolates because some biochemical tests failed during the identification process performed by the device, exhibiting divergent characteristics of the species isolated. These errors are shown in Table 4.

Fewer errors occurred when the conventional phenotypic methods were used for identification compared to the automated VITEK ${ }^{\circledR} 2$ system. Among Gram-positive cocci, the conventional phenotypic methods correctly identified 211/215 (98.1 \%) isolates and the few errors observed mainly occurred in the identification of CoNS species, showing divergent results for a given species. The conventional phenotypic methods correctly identified all yeasts $(15 / 15)$ and 164/165 (99.4 \%) Gram-negative bacilli, with the errors described in Table 4.

One hundred percent discrepant results were obtained for the identification of five isolates of Gram-positive bacilli by the VITEK ${ }^{\circledR} 2$ system (ANC card) and the genotypic identification methods.

Statistical analysis of the identification results revealed a kappa value of 0.945 ( $\mathrm{p}<0.001)$, indicating almost perfect agreement according to the criteria of Landis and Koch [18] (Table 5). 
Table 2 Comparison of the results of identification of blood culture isolates obtained with the automated VITEK ${ }^{\circledR} 2$ system, conventional phenotypic methods, and genotypic methods

\begin{tabular}{|c|c|c|c|}
\hline Microorganism isolated (number) & Automated identification & Conventional methods & Genotypic identification \\
\hline Bacillus licheniformis $(\mathrm{N}=2)$ & 0 & NP & 2 \\
\hline Corynebacterium amycolatum $(\mathrm{N}=3)$ & 0 & NP & 3 \\
\hline Enterococcus faecalis $(\mathrm{N}=8)$ & 7 & 8 & 8 \\
\hline Staphylococcus epidermidis $(N=81)$ & 71 & 81 & 81 \\
\hline Staphylococcus hominis $(\mathrm{N}=35)$ & 32 & 33 & 35 \\
\hline Staphylococcus capitis $(\mathrm{N}=18)$ & 17 & 18 & 18 \\
\hline Staphylococcus haemolyticus $(\mathrm{N}=50)$ & 49 & 48 & 50 \\
\hline Staphylococcus aureus $(\mathrm{N}=17$ ) & 17 & 17 & 17 \\
\hline Enterobacter cloacae $(\mathrm{N}=13)$ & 13 & 13 & 13 \\
\hline Proteus mirabilis $(\mathrm{N}=5)$ & 5 & 5 & 5 \\
\hline Escherichia coli $(\mathrm{N}=13)$ & 13 & 13 & 13 \\
\hline Serratia marcescens $(N=22)$ & 22 & 22 & 22 \\
\hline Acinetobacter baumannii $(\mathrm{N}=39)$ & 39 & 39 & 39 \\
\hline Acinetobacter Iwoffii $(\mathrm{N}=3)$ & 3 & 3 & 3 \\
\hline Candida albicans $(\mathrm{N}=5)$ & 5 & 5 & 5 \\
\hline Candida glabrata $(\mathrm{N}=5)$ & 5 & 5 & 5 \\
\hline Candida krusei $(\mathrm{N}=2)$ & 2 & 2 & 2 \\
\hline Candida tropicalis $(\mathrm{N}=3)$ & 3 & 3 & 3 \\
\hline Enterobacter aerogenes $(\mathrm{N}=8)$ & 8 & 8 & 8 \\
\hline Enterococcus faecium $(\mathrm{N}=4)$ & 4 & 4 & 4 \\
\hline Klebsiella pneumoniae $(\mathrm{N}=43)$ & 43 & 42 & 43 \\
\hline Morganella morganii $(\mathrm{N}=3)$ & 3 & 3 & 3 \\
\hline Pseudomonas aeruginosa $(\mathrm{N}=15)$ & 15 & 15 & 15 \\
\hline Staphylococcus cohnii $(\mathrm{N}=1)$ & 1 & 1 & 1 \\
\hline Staphylococcus warneri $(\mathrm{N}=1)$ & 1 & 1 & 1 \\
\hline Stenotrophomonas maltophilia $(\mathrm{N}=1)$ & 1 & 1 & 1 \\
\hline
\end{tabular}

NP identification not performed

Table 3 Discrepant results between the automated VITEK ${ }^{\circledR} 2$ system and the other identification methods of blood culture isolates

\begin{tabular}{llll}
\hline No. & Automated identification & Conventional methods & Genotypic identification \\
\hline 4 & Staphylococcus hominis & Staphylococcus epidermidis & Staphylococcus epidermidis \\
3 & Corynebacterium urealyticum & $\mathrm{NP}$ & Corynebacterium amycolatum \\
2 & Corynebacterium urealyticum & $\mathrm{NP}$ & Bacillus licheniformis \\
2 & Staphylococcus lentus & Staphylococcus epidermidis & Staphylococcus epidermidis \\
2 & Staphylococcus haemolyticus & Staphylococcus hominis & Staphylococcus hominis \\
1 & Enterococcus gallinarum & Enterococcus faecalis & Enterococcus faecalis \\
1 & Staphylococcus cohnii & Staphylococcus capitis & Staphylococcus capitis \\
1 & Staphylococcus haemolyticus & Staphylococcus haemolyticus & Staphylococcus epidermidis \\
1 & Staphylococcus lugdunensis & Staphylococcus epidermidis & Staphylococcus epidermidis \\
1 & Staphylococcus scuri & Staphylococcus epidermidis & Staphylococcus epidermidis \\
1 & Staphylococcus capitis & Staphylococcus epidermidis & Staphylococcus epidermidis \\
1 & Staphylococcus warneri & Staphylococcus haemolyticus & Staphylococcus haemolyticus \\
1 & Staphylococcus haemolyticus & Staphylococcus haemolyticus & Staphylococcus hominis \\
\hline
\end{tabular}


Table 4 Biochemical tests that failed during the identification process by the VITEK ${ }^{\circledR}$ system and by the conventional phenotypic methods

\begin{tabular}{|c|c|c|c|c|c|}
\hline \multirow[t]{2}{*}{ No. } & \multirow{2}{*}{$\begin{array}{l}\text { Genotypic identification } \\
\text { Identification }\end{array}$} & \multirow{2}{*}{$\begin{array}{l}\text { Conventional phenotypic } \\
\text { method } \\
\text { Identification }\end{array}$} & \multicolumn{3}{|c|}{ VITEK $^{\circledR} 2$ system } \\
\hline & & & Incorrect test & Identification & Incorrect test \\
\hline 3 & Staphylococcus epidermidis & Staphylococcus epidermidis & 0 & Staphylococcus hominis & dMNE-;TRE + \\
\hline 2 & Staphylococcus epidermidis & Staphylococcus epidermidis & 0 & Staphylococcus lentus & PolyB- \\
\hline 1 & Staphylococcus epidermidis & Staphylococcus epidermidis & 0 & Staphylococcus cohnii & SUC-; dTRE + \\
\hline 3 & Staphylococcus hominis & Staphylococcus hominis & 0 & Staphylococcus haemolyticus & PyrA + ; dMAN+ \\
\hline 2 & Staphylococcus hominis & Staphylococcus epidermidis & $\mathrm{THIO}+$ & Staphylococcus hominis & 0 \\
\hline 2 & Staphylococcus haemolyticus & Staphylococcus warneri & URE+ & Staphylococcus haemolyticus & 0 \\
\hline 1 & Enterococcus faecalis & Enterococcus faecalis & 0 & Enterococcus gallinarum & dSOR-; dRAF+ \\
\hline 1 & Staphylococcus capitis & Staphylococcus capitis & 0 & Staphylococcus cohnii & $\beta G A L+; \beta G U R+; S U C-; d$ TRE + \\
\hline 1 & Staphylococcus epidermidis & Staphylococcus haemolyticus & URE- & Staphylococcus haemolyticus & $\begin{array}{l}\text { PyrA+; URE-, PolyB-;TRE+; } \\
\text { dMNE- }\end{array}$ \\
\hline 1 & Staphylococcus epidermidis & Staphylococcus epidermidis & 0 & Staphylococcus lugdunensis & PyrA $+;$ dTRE + \\
\hline 1 & Staphylococcus epidermidis & Staphylococcus epidermidis & 0 & Staphylococcus scuri & $\begin{array}{l}\text { PolyB-; } \beta \text { GUR }+ \text {;NAG }(+) \\
\text { dMAN }+ \text {; dTRE }+\end{array}$ \\
\hline 1 & Staphylococcus epidermidis & Staphylococcus epidermidis & 0 & Staphylococcus capitis & SUC-; dMAL-;PolyB-;URE- \\
\hline 1 & Staphylococcus haemolyticus & Staphylococcus haemolyticus & 0 & Staphylococcus warneri & 0 \\
\hline 1 & Klebsiella pneumoniae & Klebsiella oxytoca & Indol+ & Klebsiella pneumoniae & 0 \\
\hline
\end{tabular}

$d M N E$ D-mannose, $d T R E$ D-trehalose, PolyB polymyxin B, SUC sucrose, PyrA L-pyrrolidonylarylamidase, $d M A N$ D-mannitol, dSOR D-sorbitol, dRAF D-raffinose, URE urea, $\beta G A L$ beta-galactosidase, THIO thioglycolatebroth, $\beta G U R$ beta-glucuronidase, $N A G N$-acetylglucosamine, 0 no errors in the tests

Table 5 Kappa value according to Landis and Koch

\begin{tabular}{ll}
\hline Kappa value & Level of agreement \\
\hline$<0.00$ & No agreement \\
$0.00-0.20$ & Slight \\
$0.21-0.40$ & Fair \\
$0.41-0.60$ & Moderate \\
$0.61-0.80$ & Substantial \\
$0.81-1.00$ & Almost perfect \\
\hline
\end{tabular}

Agreement between the conventional phenotypic methods and genotypic identification was higher than that between the genotypic method and automated identification by the VITEK ${ }^{\circledR} 2$ system (Table 6 ).

Comparison of the sensitivity of the conventional phenotypic methods and the VITEK ${ }^{\circledR} 2$ system showed a better performance of the former (Table 7).

\section{Discussion}

The need for the rapid and efficient identification of microorganisms isolated from blood cultures has encouraged studies that investigated automated identification systems to reduce the time of identification. Several of these studies have used direct inoculation from blood culture bottles, but the results were not as efficient as those obtained in studies using standard inocula from subcultures of microorganisms grown for $24 \mathrm{~h}$ on solid media. The poor performance of the VITEK ${ }^{\circledR}$ 2 system for the identification of microorganisms using direct inoculation from blood culture bottles is probably due to the small number of cells or to contamination with other microorganisms that impair the correct identification of the causative agent of infection [1922]. The VITEK system has been investigated for more than two decades and improvement of the ID-GPC (Gram-positive cocci) and ID-GNB (Gram-negative bacilli) identification cards to the GP (Gram-positive cocci) and GN (Gram-negative bacilli) cards has made the system more efficient. Wallet et al. [23] compared the old and new identification cards and found that the GP and GN cards correctly identified 235/249 (94.4\%) Gram-positive cocci and 321/331 (97 \%) Gram-negative bacilli, while the ID-GPC and ID-GNB correctly identified 218/249 (87.5 \%) and 295/331 (89.1\%) isolates, respectively.

The present study was conducted over a period of 18 months and evaluated the accuracy of the VITEK $^{\circledR} 2$ system in identifying 400 microorganisms (Gram-positive cocci, Gram-positive bacilli, Gram-negative bacilli, and yeasts) isolated from blood cultures and inoculated by the standard method onto GP, GN, YST (yeast) and ANC (Gram-positive bacilli) cards. The results were compared to genotypic identification (gold standard) and $94.7 \%$ agreement was observed. Similar rates have been reported by De Cueto et al. [24] (95.0 \%, 95/100) 
Table 6 Kappa values of agreement between automated identification by the VITEK $^{\circledR} 2$ system, the conventional phenotypic methods, and genotypic identification

\begin{tabular}{|c|c|c|c|}
\hline \multirow[t]{2}{*}{ Group } & \multirow{2}{*}{$\begin{array}{l}\text { Number } \\
\text { of isolates }\end{array}$} & \multicolumn{2}{|l|}{ Kappa } \\
\hline & & $\begin{array}{l}\text { Conventional } \\
\text { method x } \\
\text { genotypic } \\
\text { method }\end{array}$ & $\begin{array}{l}\text { Automated } \\
\text { method x } \\
\text { genotypic } \\
\text { method }\end{array}$ \\
\hline Gram-positive cocci & 255 & 0.969 & 0.904 \\
\hline CoNS & 186 & 0.969 & 0.886 \\
\hline Gram-negative bacilli & 165 & 0.993 & 1.000 \\
\hline Gram-positive bacilli & 5 & NP & 0 \\
\hline Yeasts & 15 & 1.000 & 1.000 \\
\hline Total & 400 & 0.958 & 0.945 \\
\hline
\end{tabular}

CoNS coagulase-negative staphylococci, NP not performed

and by Nakasone et al. [25] (95.8 \%, 454/474) who also used standard inocula. Studies using direct inoculation from blood cultures bottles obtained lower agreement of $91.4 \%$ [5] and $81.0 \%$ [6].

All 15 yeasts isolated during the study period were correctly identified by the VITEK ${ }^{\circledR} 2$ system. Correct identification of all yeast isolates $(56 / 56)$ has also been observed by Nakasone et al. [25]. Studies involving a larger number of strains and species found lower agreement, $92.1 \%(222 / 241)$ reported by Graf et al. [26] and $78.9 \%(277 / 351)$ by Won et al. [27].

The VITEK ${ }^{\circledR} 2$ system has shown satisfactory identification rates of Gram-negative bacilli for decades, as also observed in this study in which $100 \%$ correct identifications of the isolates were obtained. Funke et al. [28] and Ling et al. [29] analyzed 845 and 281 isolates, with correct identification rates of $84.7 \%$ (716/845) and $95 \%$ (267/281), respectively. Nakasone et al. [25], Gherardi et al. [5] and Prod'hom et al. [6] analyzed 181, 91 and 95 Gram-negative bacilli and obtained correct identifications of $96.7 \%(175 / 181), 100 \%(91 / 91)$ and $98.8 \%$ (92/95), respectively, with the VITEK ${ }^{\circledR} 2$ system.
Studies using direct inoculation from blood culture bottles reported lower rates of correct identification of 82 [30] and $93 \%$ [31]. De Cueto et al. [24] compared direct inoculation from blood cultures with inoculation from subcultures in 50 isolates. The result was $100 \%$ correct identifications for the standard method and $62 \%(31 / 5)$ correct identifications for direct inoculation. Similar results have been reported by Kerremans et al. [32] who analyzed 161 isolates; $90 \%(145 / 161)$ of the isolates were correctly identified by subculture and $80 \%$ (129/161) by direct inoculation from blood cultures.

The identification of Gram-positive cocci by the automated VITEK ${ }^{\circledR} 2$ system showed $92.6 \%$ agreement with genotypic identification, which is compatible with the rate reported by Ligozzi et al. [33] who obtained $91.5 \%$ (351/381) correct identifications. De Cueto et al. [24] obtained $100 \%(50 / 50)$ correct identifications of the isolates. Funke and Funke-Kissling [34], Nakasone et al. [25] and Chatzigeorgiou et al. [35] reported higher rates of correct identification than those obtained in this study of $94.5 \%(344 / 364), 96.1 \%(226 / 235)$ and $97.9 \%(144 / 147)$, respectively. Gherardi et al. [5] and Prod'hom et al. [6] obtained correct identifications of $75 \%(36 / 48)$ and $74 \%$ (133/180), while Lupetti et al. [36] found a rate of $89 \%$ $(49 / 55)$. These rates are lower than those observed in this study and are outside the acceptable parameter of $90 \%$ correct identifications; however, these studies used direct inoculation from blood culture bottles.

With respect to genera of Gram-positive cocci, a difference in the efficiency of the $\operatorname{VITEK}^{\circledR} 2$ system was observed. Agreement was $91.7 \%$ (11/12) for the genus Enterococcus, similar to the rates reported by Nakasone et al. [25] and Jin et al. [37]. Lower efficiencies of 77.8, $83.1,87.5,72$ and $77.8 \%$ correct identifications of strains of this genus have been observed by Ligozzi et al. [33], d'Azevedo et al. [38], Moore et al. [39] and Paim et al. [42], respectively. In the case of Staphylococcus, a higher rate of incorrect identifications was observed for CoNS isolates (91.9 \%), in agreement with Ligozzi et al. [33]

Table 7 Sensitivity and specificity of the conventional phenotypic methods and of the automated VITEK 2 system in the identification of microorganisms

\begin{tabular}{|c|c|c|c|c|}
\hline \multirow[t]{2}{*}{ Microorganism } & \multicolumn{2}{|l|}{ VITEK $^{\circledR} 2$ system } & \multicolumn{2}{|c|}{ Phenotypic methods } \\
\hline & Sensitivity (\%) & Specificity (\%) & Sensitivity (\%) & Specificity (\%) \\
\hline Enterococcus faecalis & 87.5 & 100 & 100 & 100 \\
\hline Staphylococcus capitis & 94.4 & 99.5 & 100 & 100 \\
\hline Staphylococcus cohnii & 100 & 99.0 & 100 & 100 \\
\hline Staphylococcus epidermidis & 87.6 & 100 & 100 & 98.5 \\
\hline Staphylococcus haemolyticus & 98.0 & 96.5 & 96.0 & 100 \\
\hline Staphylococcus hominis & 91.4 & 98.3 & 94.2 & 100 \\
\hline Staphylococcus warneri & 100 & 99.5 & 100 & 99.0 \\
\hline
\end{tabular}


(86 \%), Funke and Funke-Kissling [34] (93.7 \%), Kim et al. [40] (87.5\%), Delmas et al. [41] (78.8 \%), and Paim et al. [42] (72.9\%). These unsatisfactory results are due to the fact that automated identification systems are unable to perform a fully reliable differentiation between different CoNS species because of the variable expression of phenotypic characteristics in these microorganisms [43]. The slow metabolism of certain species leads to ambiguous results in their identification, a fact observed by Ligozzi et al. [33]. All Staphylococcus aureus isolates were correctly identified (17/17), as also reported in the studies of Delmas et al. [41] (6/6), Chatzigeorgiou et al. [35] (52/52), Paim et al. [42] (11/11), and Funke and Funke-Kissling [34] (45/45). Ligozzi et al. [33], who evaluated a larger number of isolates, found $99 \%$ agreement (99/100). These rates of correct identification demonstrate a satisfactory performance of the VITEK $^{\circledR} 2$ system for the identification of Staphylococcus aureus.

The failure of the ANC card to identify Gram-positive bacilli can be explained by the variability in the genera and species of these microorganisms and the consequent difficulty in developing cards that contain variable biochemical tests necessary for correct identification. These microorganisms were not identified by conventional phenotypic methods since this identification is infeasible in routine clinical microbiology because it requires numerous expensive and time-consuming biochemical tests.

The better performance of the conventional methods for CoNS identification was responsible for the higher sensitivity of these methods compared to the VITEK ${ }^{\circledR}$ 2 system. This finding can be explained by the fact that the conventional methods used consisted of specific tests for each CoNS species and by the incubation period of $72 \mathrm{~h}$, which is necessary for this correct identification since some species have a slower metabolism on some substrates.

\section{Conclusions}

The kappa values indicate reliability of the results obtained with the VITEK ${ }^{\circledR} 2$ system. Analysis of specificity showed a performance higher than $90 \%$ as required for commercial systems in clinical microbiology, demonstrating that this system is suitable for the identification of microorganisms isolated in routine clinical microbiology laboratories.

\footnotetext{
Authors' contributions

ACMM conceived and designed the study, performed the tests, analyzed and interpreted the data, and wrote the manuscript. CMCBF substantially contributed to the conception of the study and performed the statistical analyses. AMF collected the blood cultures and performed the automated identification. RSC participated in the data collection and analysis. EB identified the yeast isolates. MLRSC participated in the conception of the study, data analysis, and writing and revision of the manuscript. All authors read and approved the final manuscript.
}

\begin{abstract}
Author details
${ }^{1}$ Departamento de Microbiologia e Imunologia, Instituto de Biociências de Botucatu, UNESP-Univ. Estadual Paulista, Distrito de Rubião Junior, s/n, Botucatu, SP CEP: 18618-970, Brazil. ${ }^{2}$ Departamento de Doenças Tropicais, Faculdade de Medicina de Botucatu, UNESP-Univ. Estadual Paulista, Distrito de Rubião Junior, s/n, Botucatu, SP CEP: 18618-970, Brazil. ${ }^{3}$ Laboratório de Análises Clínicas do Hospital das Clínicas de Botucatu, Faculdade de Medicina de Botucatu, UNESP-Univ. Estadual Paulista, Distrito de Rubião Junior, s/n, Botucatu, SP CEP: 18618-970, Brazil. ${ }^{4}$ Comissão de Controle de Infecção Relacionada à Assistência à Saúde, Hospital das Clínicas, Faculdade de Medicina de Botucatu, UNESP-Univ. Estadual Paulista, Distrito de Rubião Junior, s/n, Botucatu, SP CEP: 18618-970, Brazil. ${ }^{5}$ Departamento de Clínica Médica, Faculdade de Medicina de Botucatu, UNESP-Univ. Estadual Paulista, Distrito de Rubião Junior, s/n, Botucatu, SP CEP: 18618-970, Brazil.
\end{abstract}

\section{Acknowledgements}

We thank Fundação de Amparo à Pesquisa do Estado de São Paulo (FAPESP) for financial support (Grant 2012/1566-8).

\section{Competing interests}

The authors declare that they have no competing interests.

\section{Availability of supporting data}

The data set supporting the results of this article is included within the article.

\section{Ethics approval and consent to participate}

The present study was approved by the Research Ethics Committee of Faculdade de Medicina de Botucatu, Botucatu, São Paulo State, Brazil (Protocol 347/2012-CEP).

\section{Funding}

Fundação de Amparo à Pesquisa do Estado de São Paulo (FAPESP)—Grant 2012/1566-8.

Received: 18 May 2016 Accepted: 14 July 2016

Published online: 05 August 2016

\section{References}

1. Instituto Latino Americano para Estudos da Sepse. Sepse: um problema de saúde pública. Brasília: CFM; 2015.

2. Diament D, Salomão R, Rigatto O, Gomes B, Silva E, Carvalho NB, Machado FR. Guidelines for the treatment of severe sepsis and septic shock - management of the infectious agent-diagnosis. Rev Bras Ter Intensiva. 2011;23(2):134-44.

3. Weinstein MP, Murphy JR, Reller LB, Lichtenstein KA. The clinical significance of positive blood cultures: a comprehensive analysis of 500 episodes of bacteremia and fungemia in adults. II. Clinical observations, with special reference to factors influencing prognosis. Rev Infect Dis. 1983;5(1):54-70.

4. Barenfanger J, Drake C, Kacich G. Clinical and financial benefits of rapid bacterial identification and antimicrobial susceptibility testing. J Clin Microbiol. 1999:37(5):1415-8.

5. Gherardi G, Angeletti S, Panitti M, Pompilio A, Di Bonaventura G, Crea F, Avola A, Fico L, Palazzo C, Sapia GF, Visaggio D, Dicuonzo G. Comparative evaluation of the VITEK-2 Compact and Phoenix systems for rapid identification and antibiotic susceptibility testing directly from blood cultures of Gram-negative and Gram-positive isolates. Diagn Microbiol Infect Dis. 2012;72(1):20-31.

6. Prod'hom G, Durussel C, Greub G. A simple blood-culture bacterial pellet preparation for faster accurate direct bacterial identification and antibiotic susceptibility testing with the VITEK 2 system. J Med Microbiol. 2013;62(5):773-7.

7. Cunha MLRS, Sinzato YK, Silveira LVA. Comparison of methods for the identification of coagulase negative staphylococci. Mem Inst Oswaldo Cruz. 2004;99(8):855-60.

8. Winn WC Jr, Allen SD, Janda WM, Koneman EW, Procop GW, Schreckenberger PC, Woods GL. Koneman. Diagnóstico microbiológico: texto e altlas colorido. 6th ed. Rio de Janeiro: Editora Guanabara Koogan; 2010. 
9. Hogg GM, McKenna JP, Ong G. Rapid detection of methicillin-susceptible and methicillin-resistant Staphylococcus aureus directly from positive BacT/Alert blood culture bottles using real-time polymerase chain reaction: evaluation and comparison of 4 DNA extraction methods. Diagn Microbiol Infect Dis. 2008;61 (4):446-52.

10. Fredericks DN, Relman DA. Improved amplification of microbial DNA from blood cultures by removal of the PCR inhibitor sodium polyanetholesulfonate. J Clin Microbiol. 1998;36(10):2810-6

11. McCullough MJ, Di Salvo AF, Clemons KV, Park P, Stevens DA. Molecular epidemiology of Blastomyces dermatitidis. Clin Infect Dis. 2000;30(2):328-35.

12. Barry T, Colleran G, Glennon M, Dunican LK, Gannon F. The 16S/23S ribosomal spacer region as a target for DNA probes to identify eubacteria. PCR Methods Appl. 1991;1 (1):51-6.

13. Couto I, Pereira S, Miragaia M, Sanches IS, Lencastre H. Identification of clinical staphylococcal isolates from humans by internal transcribed spacer PCR. J Clin Microbiol. 2001;39(9):3099-103.

14. Khamis A, Raoult D, La Scola B. rpoB gene sequencing for identification of Corynebacterium species. J Clin Microbiol. 2004;42(9):3925-31.

15. Gouveia C, Asensi MD, Zahner V, Rangel EF, Oliveira SM. Study on the bacterial midgut microbiota associated to different Brazilian populations of Lutzomyia longipalpis (Lutz \& Neiva) (Diptera: Psychodidae). Neotrop Entomol. 2008:37(5):597-601.

16. Kurtzman CP, Robnett CJ. Identification of clinically important ascomycetous yeasts based on nucleotide divergence in the 59 end of the largesubunit (26S) ribosomal DNA gene. J Clin Microbiol. 1997;35(5):1216-23.

17. Fletcher RH, Fletcher SW, Wagner EH. Diagnóstico. In: Fletcher RH, Fletcher SW, Wagner EH, editors. Epidemiologia Clínica. 3rd ed. Porto Alegre: Artes Médicas; 1991. p. 68-107.

18. Landis JR, Koch GG. The measurement of observer agreement for categorical data. Biometrics. 1977;33(1):159-74.

19. Fontanals D, Salceda F, Hernández J, Sanfeliu I, Torra M. Evaluation of wider system for direct identification and antimicrobial susceptibility testing of gram-negative bacilli from positive blood culture bottles. Eur J Clin Microbiol Infect Dis. 2002;21(9):693-5.

20. Waites KB, Brookings ES, Moser SA, Zimmer BL. Direct bacterial identification from positive BacT/Alert blood cultures using MicroScan overnight and rapid panels. Diagn Microbiol Infect Dis. 1998;32(1):21-6.

21. Alipour M, Hajiesmaili R, Talebjannat M, Yahyapour Y. Identification and antimicrobial resistance of Enterococcus spp. isolated from the river and coastal waters in northern Iran. Scientific World Journal. 2014; 2014:287458.

22. Waites KB, Brookings ES, Moser SA, Zimmer BL. Direct susceptibility testing with positive BacT/Alert blood cultures by using MicroScan overnight and rapid panels. J Clin Microbiol. 1998;36(7):2052-6.

23. Wallet F, Loïez C, Renaux E, Lemaitre N, Courcol RJ. Performances of VITEK 2 colorimetric cards for identification of Gram-positive and Gram-negative bacteria. J Clin Microbiol. 2005;43(9):4402-6.

24. De Cueto M, Ceballos E, Martinez-Martinez L, Perea EJ, Pascual A. Use of positive blood cultures for direct identification and susceptibility testing with the VITEK 2 system. J Clin Microbiol. 2004:42(8):3734-8.

25. Nakasone I, Kinjo T, Yamane N, Kisanuki K, Shiohira CM. Laboratory-based evaluation of the colorimetric VITEK-2 Compact system for species identification and of the Advanced Expert System for detection of antimicrobial resistances: VITEK-2 Compact system identification and antimicrobial susceptibility testing. Diagn Microbiol Infect Dis. 2007;58(2):191-8.

26. Graf B, Adam T, Zill E, Göbel UB. Evaluation of the VITEK 2 system for rapid identification of yeast and yeast-like organisms. J Clin Microbiol. 2000;38(5):1782-5.

27. Won EJ, Shin JH, Kim MN, Choi MJ, Joo MY, Kee SJ, Shin MG, Suh SP, Ryang DW. Evaluation of the BD Phoenix system for identification of a wide spectrum of clinically important yeast species: a comparison with VITEK 2-YST. Diagn Microbiol Infect Dis. 2014;79(4):477-80.

28. Funke G, Monnet D, de Bernardis C, von Graevenitz A, Freney J. Evaluation of the VITEK 2 system for rapid identification of medically relevant Gramnegative rods. J Clin Microbiol. 1998;36(7):1948-52.

29. Ling TKW, Tam PC, Liu ZK, Cheng AFB. Evaluation of VITEK 2 rapid identification and susceptibility testing system against Gram-negative clinical isolates. J Clin Microbiol. 2001;39(8):2964-6.
30. Ling TK, Liu ZK, Cheng AF. Evaluation of the VITEK 2 system for rapid direct identification and susceptibility testing of Gram-negative bacilli from positive blood cultures. J Clin Microbiol. 2003;41(10):4705-7.

31. Bruins MJ, Bloembergen P, Ruijs GJ, Wolfhagen MJ. Identification and susceptibility testing of Enterobacteriaceae and Pseudomonas aeruginosa by direct inoculation from positive BACTEC blood culture bottles into VITEK 2. J Clin Microbiol. 2004;42(1):7-11.

32. Kerremans JJ, Goessens WH, Verbrugh HA, Vos MC. Accuracy of identification and susceptibility results by direct inoculation of VITEK 2 cards from positive BACTEC cultures. Eur J Clin Microbiol Infect Dis. 2004;23(12):892-8

33. Ligozzi M, Bernini C, Bonora MG, De Fatima M, Zuliani J, Fontana R. Evaluation of the VITEK 2 system for identification and antimicrobial susceptibility testing of medically relevant Gram-positive cocci. J Clin Microbiol. 2002:40(5):1681-6.

34. Funke G, Funke-Kissling P. Performance of the new VITEK 2 GP card for identification of medically relevant Gram-positive cocci in a routine clinical laboratory. J Clin Microbiol. 2005;43(1):84-8.

35. Chatzigeorgiou KS, Siafakas N, Petinaki E, Argyropoulou A, Tarpatzi A, Bobola M, Paniara O, Velegraki A, Zerva L. Identification of staphylococci by Phoenix: validation of a new protocol and comparison with VITEK 2. Diagn Microbiol Infect Dis. 2010;68(4):375-81.

36. Lupetti A, Barnini S, Castagna B, Capria AL, Nibbering PH. Rapid identification and antimicrobial susceptibility profiling of Gram-positive cocci in blood cultures with the VITEK 2 system. Eur J Clin Microbiol Infect Dis. 2010:29(1):89-95.

37. Jin WY, Jang SJ, Lee MJ, Park G, Kim MJ, Kook JK, Kim DM, Moon DS, Park YJ. Evaluation of VITEK 2, MicroScan, and Phoenix for identification of clinical isolates and reference strains. Diagn Microbiol Infect Dis. 2011;70(4):442-7.

38. D'Azevedo PA, Cantarelli W, Inamine E, Superti S, Dias CAG. Evaluation of an automated system for the identification of enterococci. J Bras Patol Med Lab. 2004:40(4):237-9.

39. Moore DF, Zhowandai MH, Ferguson DM, McGee C, Mott JB, Stewart JC. Comparison of $16 \mathrm{~S}$ rRNA sequencing with conventional and commercial phenotypic techniques for identification of enterococci from the marine environment. J Appl Microbiol. 2006;100(6):1272-81.

40. Kim M, Heo SR, Choi SH, Kwon H, Park JS, Seong MW, Lee DH, Park KU, Song J, Kim EC. Comparison of the MicroScan, VITEK 2, and Crystal GP with $16 \mathrm{~S}$ rRNA sequencing and MicroSeq 500 v2.0 analysis for coagulasenegative Staphylococci. BMC Microbiol. 2008;23(8):233-9.

41. Delmas J, Chacornac JP, Robin F, Giammarinaro P, Talon R, Bonnet R. Evaluation of the VITEK 2 system with a variety of Staphylococcus species. J Clin Microbiol. 2008:46(1):311-3.

42. Paim TGS, Cantarelli VV, D'Azevedo PA. Performance of the VITEK 2 system software version 5.03 in the bacterial identification and antimicrobial susceptibility test: evaluation study of clinical and reference strains of Gram-positive cocci. Rev Soc Bras Med Trop. 2013:47(3):377-81.

43. Weinstein MP, Mirrett S, Pelt LV, McKinnon M, Zimmer L, Kloos W, Reller LB. Clinical importance of identifying coagulase-negative Staphylococci isolated from blood cultures: evaluation of Microscan rapid and dried overnight gram-positive panels versus a conventional reference method. J Clin Microbiol. 1998;36(7):2089-92.

44. Turton JF, Woodford N, Glover J, Yarde S, Kaufmann ME, Pitt TL. Identification of Acinetobacter baumannii by detection of the blaOXA51-like carbapenemase gene intrinsic to this species. J Clin Microbiol. 2006;44(8):2974-6.

45. Turton JF, Hyde R, Martin K, Shah J. Genes encoding OXA-134-like enzymes are found in Acinetobacter Iwoffii and A. schindleri and can be used for identification. J Clin Microbiol. 2012;50(3):1019-22.

46. Stumpf AN, Roggenkamp A, Hoffmann H. Specificity of enterobacterial repetitive intergenic consensus and repetitive extragenic palindromic polymerase chain reaction for the detection of clonality the Enterobacter cloacae. Diagn Microbiol Infect Dis. 2005;53(1):9-16.

47. Williams JM, Trope M, Caplan DJ, Shugars DC. Detection and quantitation of E. faecalis by real-time PCR (qPCR), reverse transcription-PCR (RT-PCR) and cultivation during endodontic treatment. J Endod. 2006;32(8):715-21. 
48. Doumith M, Day MJ, Hope R, Wain J, Woodford N. Improved multiplex PCR strategy for rapid assignment of the four major Escherichia coli phylogenetic groups. J Clin Microbiol. 2012;50(9):3108-10.

49. Chander Y, Ramakrishnan MA, Jindal N, Hanson K, Goyal SM. Differentiation of Klebsiella pneumoniae and K. oxytoca by multiplex polymerase chain reaction. Int J Appl Res Vet Med. 2011;9(2):138-42.

50. Kim SH, An H, Visessanguan W, Benjakul S, Morrissey MT, Su YC, Pitta TP. Molecular detection of a histamine former, Morganella morganii, in Albacore, Mackrel, Sardine, and a processing plant. JFS. 2003;68(2):453-7.

51. Belas R, Schneider R, Melch M. Characterization of Proteus mirabilis precocious swarming mutants: identification of rsbA, encoding a regulator of swarming behavior. J Bacteriol. 1998;180(23):6126-39.

52. Jeong ES, Lee KS, Heo SH, Seo JH, Choi YK. Triplex PCR for the simultaneous detection of Pseudomonas aeruginosa, Helicobacter hepaticus and Salmonella typhimurium. Exp Anim. 2011;60(1):65-70.
53. Polson SW, Higgins JL, Woodley CM. PCR-based assay for detection of four coral pathogens. In: Proceedings of the 11 th international coral reef symposium, Ft. Lauderdale. Florida. 2008. p. 247-51.

54. Martineau F, Picard FJ, Roy PH, Ouellette M, Bergeron MG. Species-specific and ubiquitous-DNA-based assays for rapid identification of Staphylococcus aureus. J Clin Microbiol. 1998;6(3):618-23.

55. Stenotrophomonas maltophilia MLST Databases. http://pubmlst.org/ smaltophilia/info/primers.shtml. Accessed 6 Apr 2016.

\section{Submit your next manuscript to BioMed Central and we will help you at every step:}

- We accept pre-submission inquiries

- Our selector tool helps you to find the most relevant journal

- We provide round the clock customer support

- Convenient online submission

- Thorough peer review

- Inclusion in PubMed and all major indexing services

- Maximum visibility for your research

Submit your manuscript at www.biomedcentral com/submit

(O) Biomed Central 